\title{
Autoria e competência digital de idosos: uma revisão sistemática da literatura acerca dos conceitos
}

\author{
Authorship and competence digital of elderly: a systematic review of \\ the literature on the concepts
}

\section{Autoria y competencia digital de personas mayores: revisión sistemática de la literatura sobre los conceptos}

Bruna Kin Slodkowski ${ }^{1}$; Jacqueline Mayumi Akazaki²; Leticia Rocha Machado ${ }^{3}$; Patricia Alejandra Behar ${ }^{4}$

\section{RESUMO}

O artigo tem por objetivo analisar a autoria e competências digitais de idosos no contexto da educação. 0 número de ferramentas digitais desenvolvidas para a produção de materiais digitais cresce anualmente e, em paralelo, o interesse em criar conteúdo por idosos. Assim, é importante, investigar sobre o processo de autoria digital dos seniores nesse contexto. Nesta pesquisa, compreende-se que a autoria digital é uma competência. A metodologia adotada foi a revisão sistemática da literatura na qual se utilizou como fonte de pesquisa nove bases no período entre 2015 e 2020. Foram analisados 138 artigos sobre a temática, sendo que somente seis passaram pelos critérios de inclusão. Os dados apontaram que nenhum dos estudos compreendem a autoria digital como uma competência para idosos. A partir disso, foi possível perceber uma lacuna entre a conexão dos conceitos de competências, pois em $83,35 \%$ dos estudos estão dissociados. Por fim, constatou-se que em $100 \%$ das pesquisas a inclusão digital de idosos surge através de cursos educacionais, no qual é possível ensinar acerca das tecnologias digitais como parte de um processo para a construção de competências digitais.

Palavras-chave: Autoria Digital; Idosos; Competências Digitais; Revisão sistemática da literatura.

\begin{abstract}
The article aims to analyze about the authorship and digital competencies of the elderly in the context of education. The number of digital tools developed for the production of digital materials grows annually and, in parallel, the interest in creating content by seniors. Thus, it is important to investigate the seniors' digital authorship process in this context. In this research, it is understood that digital authorship is a competence. The methodology adopted was the systematic review of the literature in which 9 databases were used as a research source in the period between 2015 and 2020. 138 articles on the subject were analyzed, and only 6 passed the inclusion criteria. The data showed that none of the studies understand the digital authorship as a competency for seniors. From this, it was possible to notice a gap between the connection of the concepts of competences, as in $83.35 \%$ of the studies they are dissociated. Finally, it was found that in $100 \%$ of the surveys
\end{abstract}

\footnotetext{
${ }^{1}$ Mestranda e pesquisadora do Programa de Pós-graduação em Educação da Universidade Federal do Rio Grande do Sul (UFRGS), Porto Alegre/RS- Brasil. E-mail: brunakinnuted@gmail.com

${ }^{2}$ Doutoranda e pesquisadora no Programa de Pós-Graduação em Informática na Educação da Universidade Federal do Rio Grande do Sul (UFRGS), Porto Alegre/RS- Brasil. E-mail: jacquelineakazaki@gmail.com

${ }^{3}$ Doutora em Educação e professora colaboradora da Universidade Federal do Rio Grande do Sul (UFRGS) e professora visitante da Universidade Federal Santa Catarina (UFSC), Porto Alegre/RS- Brasil. E-mail: leticiarmachado@yahoo.com.br

${ }^{4}$ Doutora em Ciência da computação e professora Titular da Faculdade de Educação e dos Cursos de PósGraduação em Educação (PPGEdu) e em Informática na Educação (PPGIE) da Universidade Federal do Rio Grande do Sul (UFRGS), Porto Alegre/RS- Brasil. E-mail: pbehar@terra.com.br
} 
the digital inclusion of the elderly arises through educational courses, in which it is possible to teach about digital technologies as part of a process for the construction of digital competencies.

Keywords: Digital authorship; Elderly; Digital Competencies; Systematic literature review.

\section{RESUMEN}

El artículo tiene como objetivo analizar la autoría y lãs competências digitales de las personas mayores em el contexto de la educación. El número de herramientas digitales desarrolladas para la producción de materiales digitales crece anualmente $y$, en paralelo, el interes em la creación de contenidos por parte de las personas mayores. Por tanto, es importante investigar el proceso de autoría digital de las personas mayores en este contexto. En esta investigación se entiende que la autoría digital es una competencia. La metodología adoptada fue la revisión sistemática de la literatura en la que se utilizaron 9 bases de datos como fuente de investigación en el período comprendido entre 2015 y 2020. Se analizaron 138 artículos sobre el tema y solo 6 pasaron los criterios de inclusión. Los datos mostraron que ninguno de los estudios comprende la autoría digital como competencia para personas mayores. A partir de esto, se pudo notar una brecha entre la conexión de los conceptos de competencias, ya que en el $83,35 \%$ de los estudios se encuentran disociados. Finalmente, se encontró que en el $100 \%$ de las encuestas la inclusión digital de las personas mayores surge a través de cursos educativos, em los que es posible enseñar sobre tecnologías digitales como parte de un proceso de construcción de habilidades digitales.

Palabras clave: Autoría digital; Ancianos; Habilidades digitales; Revisión sistemática de la literatura.

\section{INTRODUÇÃO}

No cenário brasileiro os dados demográficos vêm se alterando em função do aumento do público mais velho. Segundo a Fundação Getúlio Vargas (2020), 14,05\% da população do país é constituída por idosos. Em paralelo a isso, constata-se uma ampliação no acesso às tecnologias digitais na qual estima-se que $93 \%$ dos brasileiros dispõem de acesso ao telefone celular e $27 \%$ ao computador portátil nos domicílios (CETIC, 2018). Em decorrência, há significativas transformações tecnológicas acerca da configuração de um perfil societário ativo. Nesse sentido, existe uma parcela de idosos que demonstram interesse em aprender a utilizar essas tecnologias digitais, visto que estão presentes em seu cotidiano. Dessa forma, essa necessidade abrange tanto a construção de materiais digitais quanto a divulgação dos mesmos como, por exemplo, vídeos, fotos, bem como suas montagens com emojisi, frases e áudios. Entretanto, referente à construção de conteúdos digitais, a maioria das criações está relacionada à imagens com 25\%, seguido de textos e vídeos (14\%) e músicas (3\%) (CETIC, 2019). Pode-se perceber que no contexto brasileiro o consumo desses materiais é maior do que sua produção.

Em vista disso, é relevante, cada vez mais, ressignificar o uso das tecnologias digitais no âmbito educacional de modo a oportunizar que os idosos possam construir Competências Digitais (CD) e serem autores digitais para se inserirem e atuarem na sociedade. Assim, o público sênior, por meio da participação em cursos de inclusão digital, pode construir um conjunto de conhecimentos, habilidades e atitudes acerca dessas ferramentas digitais de criação dos materiais que oportunizam a autoria digital.

Portanto, a questão norteadora desta pesquisa foi analisar a autoria e competências digitais de idosos no contexto da educação. Em relação à relevância desta investigação destaca-se a identificação e discussão acerca de uma lacuna entre os conceitos de competências e autoria digital. Dessa forma, 
o presente artigo é dividido em seis seções. Na primeira, é apresentada a introdução, com a contextualização do assunto, bem como seus objetivos. A segunda discute o processo de construção de materiais por idosos com foco nos conceitos de autoria e competências digitais. Na terceira, é descrita a metodologia da pesquisa, com suas etapas de desenvolvimento. Na penúltima seção, os resultados coletados são analisados e discutidos. Por último, traz-se as considerações finais seguidas das referências utilizadas no presente estudo.

\section{COMPETÊNCIAS DIGITAIS E AUTORIA DE IDOSOS: UM FOCO NA CONSTRUÇÃO DE MATERIAIS DIGITAIS}

O contexto demográfico brasileiro passa por um aumento do público mais velho que se encontra com uma expectativa de vida de 76,6 anos (IBGE, 2020). Paralelamente, percebe-se a ampliação do acesso às tecnologias digitais no qual $97 \%$ dos idosos brasileiros acessam a internet para se informar sobre assuntos de interesse, acessar redes sociais e fazer compras (BARBOSA, 2021). Nesse sentido, esse contato com as tecnologias vem despertando o interesse de idosos a respeito da criação de materiais digitais. Por conseguinte, no contexto educacional, os cursos de inclusão digital têm oportunizado espaços de construção de competências digitais. Os materiais digitais (MD) são qualquer conteúdo produzido por meio dos recursos das tecnologias digitais (smartphones, tablets ou notebooks) ou em ferramentas de autoria digital, tais como, apresentações, sites, aplicativos, mapa conceitual, vídeos, histórias em quadrinho, entre outros (BRANCO, 2017). Essa perspectiva, de evolução da internet, propiciou o surgimento de um novo perfil: o autor digital.

A autoria de materiais pode ser associada a qualquer tipo de produção, seja oral, escrita, impressa, artística, digital (SLODKOWSKI et al., 2019). Por conseguinte, o público mais velho, ao construírem materiais digitais, podem se expressar e participar de uma sociedade tecnologicamente ativa.

No entanto, para desenvolver esse conteúdo é necessário conhecer ferramentas de autoria, saber utilizá-las, estar atento às questões de segurança e privacidade na internet bem como compartilhar essas produções. Nessa perspectiva, observa-se que o processo de produção autoral de materiais digitais por idosos envolve a construção de competências digitais através da mobilização de um conjunto de conhecimentos, habilidades e atitudes (CHA) frente a uma situação nova (SLODKOWSKI, 2019). As competências digitais podem ser definidas como "[...] a utilização segura, crítica e criativa das Tecnologias de Informação e Comunicação para alcançar objetivos mais amplos relacionados com o emprego, a educação, o trabalho, o lazer, a inclusão e a participação na sociedade" (PATRÍCIO; OSÓRIO, 2017, p. 3).

Perrenoud (1999), ressalta que a construção de competências serve para enfrentar situações cotidianas de modo a dar significado ao que foi aprendido, pois permite relacionar o conhecimento com a sua experiência. Logo, no contexto educativo, quanto mais significativa for a aprendizagem, mais será possível que os alunos apliquem em diversas situações, o que torna funcional os conhecimentos (ZABALA; ARNAU, 2020). Desse modo, as CD estão ligadas ao domínio tecnológico, mobilizando o CHA com o objetivo de solucionar ou resolver problemas em meios digitais (SILVA; BEHAR, 2019; MACHADO; BEHAR, 2013).

Por outro lado, o conceito de autoria é abordado por diversos pesquisadores, mas há uma predominância na área das linguagens e, atualmente, na perspectiva digital em função das novas possibilidades de expressão (TEIXEIRA; ANDRADE, 2020). A noção de autoria surge em 1967 por um 
ensaio intitulado $A$ morte do autor de Roland Barthes. Nessa obra, é questionada a necessidade de autoria em textos escritos. De acordo com Foucault (2009), as obras se tornaram objetos de apropriação para que a sociedade pudesse, através da identificação do autor como dono de sua produção, identificar e punir quando os discursos fossem transgressores.

Dessa forma, inicialmente a atribuição de autoria tinha como finalidade vigiar e punir os detentores de ideias consideradas impróprias. Porém, nesta obra o filósofo não cita e tampouco relaciona a função do autor com o uso das tecnologias digitais, todavia aborda questões essenciais para compreender e discutir sobre o tema na era digital. Atualmente, percebe-se um novo fenômeno em relação à autoria: a necessidade de ser visto e reconhecido pela sociedade. Por isso, a autoria adquiriu o papel de reconhecimento, expressão, participação social e valorização.

Neste contexto, a educação passou a incluir este conceito nas suas metodologias e práticas pedagógicas, já que se observou que, através da autoria digital, seria possível propiciar ao aluno uma ruptura paradigmática, no qual o aprendiz pudesse ser ator principal ou coautor do processo de criação e inovação no virtual. Menezes (2013), ainda ressalta que o ser humano tem potencial para estar em constante ato de criação e se expressar de diferentes formas. Se tratando do público idoso, as criações autorais podem contribuir na autovalorização e autoestima (MACHADO, 2019).

Portanto, a Autoria Digital é compreendida como uma competência que permite o aluno ser protagonista do seu aprendizado e que pode ser aperfeiçoada ao longo da vida, inclusive na velhice (ANDRÉ, 2018). De modo complementar, a Autoria Digital pode ser definida como um grupo de competências digitais que se referem à capacidade de usar as tecnologias com autonomia e criticidade a fim dos idosos criarem distintos materiais digitais (SLODKOWSKI, 2019). Ademais, por meio da Autoria Digital, a autora (2019) compreende que o público sênior pode atuar na sociedade de modo mais crítico, criativo, seguro e autoral.

Nessa perspectiva, a inclusão digital de idosos se configura como uma possibilidade pedagógica de construção de conhecimentos, habilidades e atitudes relacionadas à produção de materiais digitais. Portanto, a fim de identificar e sintetizar as informações disponíveis sobre os conceitos de competências digitais e, especificamente, sobre a autoria digital de idosos no contexto da educação, são abordadas, a seguir, a metodologia desta pesquisa.

\section{METODOLOGIA}

A metodologia desse estudo é a Revisão Sistemática da Literatura (RSL) na qual foi adaptado às diretrizes de Kitchenham e Charters (2007). A pesquisa foi realizada de outubro a dezembro de 2020. Assim, foram estruturadas em três passos, sendo a primeira a de planejamento. No primeiro ocorreu a identificação da necessidade de uma revisão sistemática para a área da Educação. No segundo, a condução, teve como finalidade identificar e filtrar apenas artigos relevantes aos objetivos deste estudo. Além disso, realizou-se também a extração dos dados dos estudos selecionados. Por fim, o último passo, foi à apresentação dos dados. Nesse sentido, os mesmos foram analisados a fim de responder às questões de pesquisas ilustradas na Figura 1. 
Figura 1. Passos da revisão sistemática da literatura

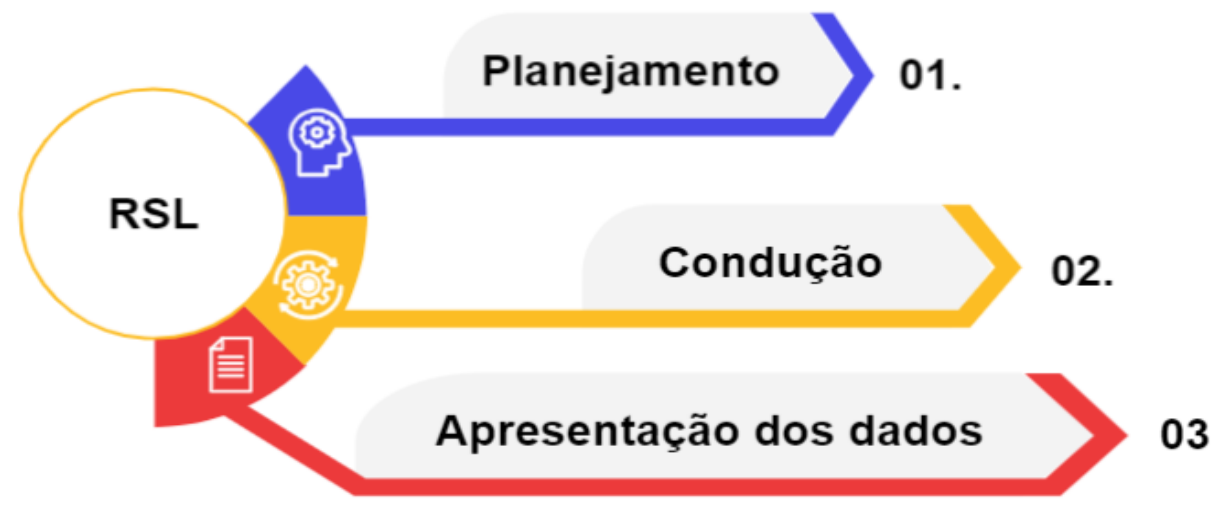

Fonte: as autoras (2021) adaptado de Kitchenham e Charters (2007)

Desse modo, para realizar esta revisão sistemática utilizou-se como fonte de pesquisa cinco bases internacionais (ACM ${ }^{i i}$, Science Directiii, Scieloiv, Google Acadêmicov e Scopus ${ }^{\mathrm{vi}}$ ) e quatro nacionais (Revista Estudos Interdisciplinares sobre o envelhecimentovii, SABI ${ }^{\text {viii }}$, Revista Ciência e Educaçãoix e Educação em Revistax), através das seguintes expressões de busca: competência digita OR autoria digital AND idoso; digital competence OR digital authorship AND elderly, competencia digital OR autoría digital $Y$ ancianos da que foram aplicados nos títulos, resumos e palavras-chave dos artigos durante as consultas. Cabe ressaltar que as bases de busca internacionais foram escolhidas por serem fontes relevantes de busca, pois abrigam conteúdos científicos que são revisados por pares. No que tange a escolha das bases nacionais, buscaram-se revistas que compreendiam a temática da educação, educação associada às tecnologias digitais e envelhecimento possuindo todas com Qualis A.

A seleção de artigos foi realizada por meio de critérios de inclusão e de exclusão conforme especificam as diretrizes de Kitchenham e Charters (2007). O Quadro 1 apresenta as questões de pesquisa.

Quadro 1. Questões de pesquisa

\begin{tabular}{|c|l|}
\hline Número de identificação & \multicolumn{1}{c|}{ Questão de pesquisa } \\
\hline Q1 & O que os autores entendem por Autoria Digital? \\
\hline Q2 & O que os autores entendem por Competências? \\
\hline Q3 & $\begin{array}{l}\text { Quais características/aspectos dos idosos são consideradas nos estudos } \\
\text { sobre a Autoria Digital em relação ao contexto educacional? }\end{array}$ \\
\hline Q4 & $\begin{array}{l}\text { Quais as principais limitações, desafios e oportunidades de pesquisa } \\
\text { relacionadas à área de educação? }\end{array}$ \\
\hline
\end{tabular}

Fonte: as autoras (2021)

Em relação aos critérios de inclusão e exclusão foram delineados alguns que possibilitasse atender as necessidades da pesquisa, bem como auxiliar na aproximação mais precisa das questões delineadas, conforme apresentado nos Quadros 2 e 3 a seguir. 
Quadro 2. Critério de Inclusão

\begin{tabular}{|c|l|}
\hline CI1 & $\begin{array}{l}\text { O artigo aborda as competências digitais e/ou a Autoria Digital no contexto da educação } \\
\text { de idosos como temática principal. }\end{array}$ \\
\hline CI2 & Artigo publicado no intervalo de tempo escolhido para a análise \\
\hline CI3 & Artigo publicado em revistas científicas \\
\hline CI4 & Artigo no idioma Inglês, português ou espanhol \\
\hline CI5 & Acesso gratuito ao texto completo \\
\hline CI6 & $\begin{array}{l}\text { O termo de busca está presente em pelo menos um dos seguintes metadados do artigo: } \\
\text { título, resumo ou palavras-chave }\end{array}$ \\
\hline
\end{tabular}

Fonte: as autoras (2021)

Quadro 3. Critérios de Exclusão

\begin{tabular}{|c|l|}
\hline CE1 & $\begin{array}{l}\text { O artigo não é um estudo primário (ex. revisões sistemáticas e mapeamentos } \\
\text { sistemáticos) }\end{array}$ \\
\hline CE2 & Artigo duplicado (apenas o mais atual será incluído) \\
\hline CE3 & Artigo não aborda o público-alvo (idosos) \\
\hline CE4 & $\begin{array}{l}\text { O artigo não aborda as competências digitais e/ou a Autoria Digital no contexto da } \\
\text { educação de idosos como temática principal. }\end{array}$ \\
\hline
\end{tabular}

Fonte: as autoras (2021)

Além disso, foi utilizado cinco filtros de busca: (i) Últimos cinco anos (2015 a 2020); (ii) Em inglês, português ou espanhol; (iii) Somente artigos revisados por pares em revistas; (iv) Acesso público ou disponível por meio do portal de periódicos da Coordenação de Aperfeiçoamento de Pessoal de Nível Superior (CAPES) via Comunidade Acadêmica Federada (CAFe) e (v) Educação, Informática na Educação, Gerontologia. Desse modo, os artigos selecionados tiveram os dados extraídos. Para isso, foram utilizadas duas estratégias de extração: a aplicação de um formulário de extração que pode ser encontrado neste

link https://docs.google.com/spreadsheets/d/1N6GV2zUieuewLoLAthUmDsIAZOndwN1KDNCAaXc28VY/e dit\#gid=0 e a mineração textual.

Na seção seguinte é apresentada a análise e discussão dos trabalhos selecionados na revisão sistemática.

\section{DISCUSSÃO E ANÁLISE DOS RESULTADOS}

Nesta seção são apresentados os resultados e análises da revisão sistemática da literatura. Inicialmente foram identificados 138 artigos através da inserção dos textos de busca nos nove repositórios e revistas definidas. Após aplicar os cinco filtros de busca restaram 72 estudos. 0 volume de artigos obtidos nessa atividade contou com a aplicação dos critérios de inclusão e exclusão, sendo que 21 artigos foram do Science Direct rejeitados pelos seguintes critérios: CI5 (dois artigos) e CE3 (dezenove artigos); seis do SABI rejeitados pelos seguintes critérios: CI6 (cinco artigos), CE6 (um artigo); um da Scopus e foi rejeitado pelo critério CE4; 38 do Google Acadêmico rejeitados pelos seguintes critérios: CI3 (25 artigos), CI5 (dois artigos), CI6 (quatro artigos), CE2 (um artigo), CE3 (um artigo), CE4 (cinco artigos). Assim, no total seis artigos (Google Acadêmico) foram selecionados. 
Para responder às questões de pesquisa realizou-se a leitura dos artigos selecionados e sintetizados no Quadro 4.

Quadro 4: Lista de artigos aceitos

\begin{tabular}{|c|c|c|c|}
\hline $\begin{array}{c}\text { Código } \\
\text { do } \\
\text { artigo }\end{array}$ & Ano & Referência & Resumo \\
\hline $\mathrm{A} 1$ & 202 & $\begin{array}{l}\text { MACHADO, Leticia Rocha.; SONEGO, } \\
\text { Anna Helena.; RIBEIRO, Ana Carolina } \\
\text { Ribeiro.; MENDES, Jozelina Silva da } \\
\text { Silva.; BEHAR, Patricia Alejandra. Autoria } \\
\text { Digital de idosos: a produção de } \\
\text { infográficos em um curso de inclusão } \\
\text { digital. Estud. interdiscipl. envelhec., } \\
\text { Porto Alegre, v. 25, n. 1, p. 7-20, } 2020 . \\
\text { Disponível em: } \\
\text { <https://seer.ufrgs.br/RevEnvelhecer/arti } \\
\text { cle/view/89047>. Acesso em: } 18 \text { jan. } \\
\text { 2021. }\end{array}$ & $\begin{array}{l}\text { O estudo analisa as contribuições da autoria } \\
\text { digital de um grupo de idosos através da } \\
\text { produção de infográficos. Como resultados } \\
\text { destacaram que apesar das dificuldades de } \\
\text { utilizar a ferramenta digital a maioria } \\
\text { mostrou desejo de usar novamente. }\end{array}$ \\
\hline$A 2$ & 2019 & $\begin{array}{l}\text { MACHADO, Leticia Rocha.; MENDES, } \\
\text { Jozelina Silva da Silva.; KRIMBERG, } \\
\text { Laura.; SILVEIRA, Clóvis.; BEHAR, } \\
\text { Patricia Alejandra. Competência digital } \\
\text { de idosos: mapeamento e avaliação. } \\
\text { ETD-Educação Temática Digital, } \\
\text { Campinas, São Paulo. v.21 n.4, p.941- } \\
959 \text { out./dez. 2019. Disponível em: } \\
\text { <https://periodicos.sbu.unicamp.br/ojs/in } \\
\text { dex.php/etd/article/view/8652536>.Acess } \\
\text { o em: } 18 \text { jan. } 2021 .\end{array}$ & $\begin{array}{l}\text { A pesquisa mapeia e analisa a competência } \\
\text { digital Segurança e a Privacidade na Internet } \\
\text { em idosos participantes de um curso de } \\
\text { inclusão digital. Quanto aos resultados } \\
\text { apontam a necessidade de desenvolver tanto } \\
\text { o Letramento quanto a Fluência Digital a fim } \\
\text { de que os idosos utilizem a internet de modo } \\
\text { seguro e mantendo a privacidade no espaço } \\
\text { virtual. }\end{array}$ \\
\hline A3 & 2019 & $\begin{array}{l}\text { SLODKOWSKI, Bruna Kin; MACHADO, } \\
\text { Leticia Rocha.; MENDES, Jozelina Silva da } \\
\text { Silva.; BEHAR, Patricia Alejandra. Autoria } \\
\text { digital de cybersêniors: um estudo de } \\
\text { caso sobre a construção de vídeos. } \\
\text { Informática Na Educação: teoria e } \\
\text { prática, Porto Alegre, v. 22, n. 3, p. 12- } \\
\text { 25, set./dez. 2019. Disponível } \\
\text { em:<https://seer.ufrgs.br/InfEducTeoriaP } \\
\text { ratica/article/view/86995>. Acesso em: } \\
19 \text { jan. } 2021 .\end{array}$ & $\begin{array}{l}\text { O artigo investiga de que forma a construção } \\
\text { de vídeos autorais contribuem para o } \\
\text { envelhecimento ativo e o desenvolvimento } \\
\text { da autonomia de cybersêniors em um curso } \\
\text { de inclusão digital. Os dados indicaram que a } \\
99 \% \text { dos idoso consideraram satisfatória a } \\
\text { construção dos materiais digitais, destacando } \\
\text { o planejamento como um dos elementos } \\
\text { principais do processo de construção. }\end{array}$ \\
\hline A4 & 2019 & $\begin{array}{l}\text { GIL, Henrique. Nativos digitais, migrantes } \\
\text { digitais e adultos mais idosos: pontes } \\
\text { para a infoinclusão. Revista Educação, } \\
\text { Psicologia e Interfaces. v. } 3 \text { n. } 2 \text {. } \\
\text { 2019. Disponível em: } \\
\text { <https://educacaoepsicologia.emnuvens. } \\
\text { com.br/edupsi/article/view/152>. Acesso } \\
\text { em: } 19 \text { jan. } 2021 .\end{array}$ & $\begin{array}{l}\text { O estudo realiza uma reflexão acerca dos } \\
\text { conceitos literacia e competência digital a fim } \\
\text { de compreender quais competências os } \\
\text { cidadãos devem possuir para exercer seus } \\
\text { direitos e deveres cívicos. Logo, os dados } \\
\text { indicaram grande taxa de info-exclusão dos } \\
\text { idosos. }\end{array}$ \\
\hline
\end{tabular}




\begin{tabular}{|c|c|c|c|}
\hline A5 & 2016 & $\begin{array}{l}\text { MACHADO, L. R.; GRANDE, T. P. F.; } \\
\text { BEHAR, P. A.; LUNA, F, M, R. } \\
\text { Mapeamento de competências digitais: a } \\
\text { inclusão social dos idosos. ETD: } \\
\text { Educação Temática Digital, v. 18, p. 903- } \\
\text { 921, 2016. Disponível em: } \\
\text { <https://periodicos.sbu.unicamp.br/ojs/in } \\
\text { dex.php/etd/article/view/8644207>. } \\
\text { Acesso em: } 20 \text { jan. } 2021 .\end{array}$ & $\begin{array}{l}\text { A pesquisa efetua um mapeamento de } \\
\text { competências digitais de idosos em cursos de } \\
\text { inclusão digital. Com base nos dados } \\
\text { apresentados as autoras mapearam cinco } \\
\text { competências organizadas em três grupos: } \\
\text { Alfabetização digital, Letramento digital e } \\
\text { Fluência digital. Assim, evidenciaram que as } \\
\text { principais neste grupo são: Recursos básicos } \\
\text { da internet; Pesquisa na Web; } \\
\text { Comunicação através do e-mail; Informação } \\
\text { online confiável e Resiliência Virtual. }\end{array}$ \\
\hline A6 & 205 & $\begin{array}{l}\text { PATRÍCIO, Maria Raquel.; OSÓRIO, } \\
\text { António. Inclusão digital com } \\
\text { aprendizagem intergeracional. Challenges } \\
\text { 2015: Meio Século de TIC na Educação, } \\
\text { Half a Centuryof ICT in Education. } \\
\text { p.795-809, 2015. Disponível em: } \\
\text { <https://www.researchgate.net/publicati } \\
\text { on/305730368_Inclusao_digital_com_apr } \\
\text { endizagem_intergeracional>. Acesso em: } \\
21 \text { jan. 2021. }\end{array}$ & $\begin{array}{l}\text { O artigo apresenta a aprendizagem } \\
\text { intergeracional no contexto da inclusão } \\
\text { digital de idosos como um recurso para a } \\
\text { aquisição e desenvolvimento de } \\
\text { competências digitais. Desse modo o } \\
\text { objetivo é apresentar o contributo da } \\
\text { aprendizagem intergeracional para a inclusão } \\
\text { digital das pessoas mais velhas. Em relação } \\
\text { aos dados apontaram que a aprendizagem } \\
\text { intergeracional mediada pelo uso das } \\
\text { tecnologias contribui para uma sociedade } \\
\text { mais inclusiva digitalmente. }\end{array}$ \\
\hline
\end{tabular}

Fonte: as autoras (2021)

$\mathrm{Na}$ extração dos dados foram analisadas as quatro questões de pesquisa: 1) O que os autores entendem por Autoria Digital?; 2) O que os autores entendem por Competências?; 3) Quais características/aspectos dos idosos são consideradas nos estudos sobre a Autoria Digital em relação ao contexto educacional?; 4) Quais as principais limitações, desafios e oportunidades de pesquisa relacionadas a área de educação? Para responder o objetivo da pesquisa, cinco categorias foram desenvolvidas, conforme será abordado a seguir.

\subsection{Autoria Digital}

Em relação à definição de Autoria Digital, verifica-se que $50 \%$ dos estudos não contemplam o conceito (A2; A5: A6). Por outro lado, 33,33\% abordam o tema, porém com definições distintas (A1; A3). Em $16,67 \%$ a definição não fica clara (A4).

Desse modo, em A1 os autores definem a Autoria Digital como "[...] a construção de todo material, como texto, imagem, sons, gráficos, infográficos, mapas, vídeos que pode ser publicado através do meio digital (MACHADO et al., 2020, p.10)". Nessa perspectiva, a pesquisa A3, apresenta como qualquer tipo de produção, tanto oral, escrita, impressa, artística, digital que está inserido em um contexto multimídia e hipertextual da internet. A partir disso, observa-se que as perspectivas teóricas de $A 1$ e $A 3$ são semelhantes na exposição do termo.

Ao invés disso, em A4, o conceito de autoria digital aparece associado à literacia no qual faz menção a questão de difusão e plágio de materiais como textos, imagens, gráficos e entre outros, ou seja, não fica explícita uma definição conceitual. Entretanto, esse estudo aproxima o termo com relação ao compartilhamento do conteúdo e, sobretudo, aos cuidados com direitos autorais e plágio que nas pesquisas anteriores não foi apontado. 
Portanto, por meio da análise desses dados se percebe uma falta de definição a respeito do conceito de autoria digital e, através da ressalva da pesquisa de A4, observa-se a necessidade de análises e discussões acerca dos direitos autorais associados ao referido conceito.

\subsection{Competências e Competências Digitais}

A respeito da definição de Competências, nota-se que 66,68\% das investigações apresentam a base teórica sobre o termo (A2; A4; $A 5 ; A 6)$. Contudo, 33,33\% das pesquisas não explicitaram o conceito $(A 1 ; A 3)$.

Quanto à definição, em A2 fica evidente, pois utilizam o conceito de competência baseado em Behar (2013) na qual é constituída por três elementos: conhecimento (saber), habilidade (saber fazer) e atitude (saber ser). Nesse viés, em A5, o conceito de competência também é subsidiado em Behar (2013) e Perrenoud (2013) sendo compreendido como:

[...] a mobilização conjunta de recursos cognitivos específicos (mas não fixos ou exclusivos de determinada competência) para enfrentar as mais diversas situações problemas. Para tanto, é importante a relação de três elementos: conhecimentos, habilidades e atitudes (CHA). Tais recursos estão respectivamente ligados ao saber (conhecer), saber fazer e saber ser (MACHADO et al., 2016, p. 907).

Em contrapartida, em A4, há uma distinção entre o conceito de competências e de literacia digital afirmando que esta ultrapassa a utilização prática e instrumental de TD. Esse também apresenta o quadro DigComp 2.0 de Lucas e Moreira (2017) no qual consta um destaque para a competência Criação de Conteúdo digital.

Por fim, em A6, percebe-se claramente a definição de competências digitais utilizadas pelos autores sendo baseadas na Comissão Europeia (2013) e que

"[...] envolvem o uso confiante e crítico da sociedade da informação tecnologia (TIC) na população em geral e fornecer o contexto necessário (ou seja, o conhecimento, habilidades e atitudes) para trabalhar, viver e aprender na sociedade do conhecimento. As competências digitais são definidas como a capacidade de acessar mídia digital e TIC, para compreender e avaliar criticamente diferentes aspectos da mídia digital e conteúdo de mídia e para se comunicar de forma eficaz em uma variedade de Contextos influenciados pelas TIC (COMISSÃO EUROPEIA, 2013, parágrafo 1$)^{\prime \prime}$.

Logo é possível constatar que dois estudos (A2 e A5) parte das mesmas premissas teóricas na conceituação de competências. Entretanto, em A4 e A5 há utilização em outro viés específico acerca das Competências Digitais.

\subsection{Características dos idosos no contexto educacional}

No que se refere às características dos idosos que são consideradas nos estudos sobre a Autoria Digital, em relação ao contexto educacional, constatou-se cinco aspectos. Assim, 16,67\% dos estudos indicaram a motivação para aprender sobre as TD (A6); 16,67\% ressaltam a relevância do conteúdo dos materiais (A1); 16,67\% mencionam o tema de interesse do sênior (A3); 16,67\% apresentam a pertinência do público desenvolver três competências (Alfabetização, o Letramento e a Fluência Digital) (A2) e, por fim, 33,33\% não apresentam as características dos idosos que são consideradas para autoria digital na educação (A4; A5). 
Na pesquisa A1 foi possível encontrar um aspecto que se refere ao conteúdo dos materiais tendo em vista que podem ser relevantes para o grupo e a sociedade. Nessa perspectiva, Machado et al. (2020, p. 10) indicam que "[...] o desenvolvimento da autoria digital pode proporcionar aos idosos uma autoavaliação e autovalorização por possibilitar a expressão, percepção e experiências adquiridas ao longo da vida".

Em A2 apontaram a importância de desenvolver três grupos de competências: a Alfabetização, o Letramento e a Fluência Digital e seus respectivos CHA. De modo sintético descreveram que:

- A Alfabetização Digital abrange os elementos necessários aos iniciantes;

- O Letramento Digital necessita de atitudes reflexivas e críticas;

- E a Fluência Digital é considerada a mais completa para o uso das tecnologias digitais.

No entanto, em A3, destacaram o potencial para produzir diversos tipos de materiais a respeito de temas de seu interesse e exemplificam com a construção de vídeos. A investigação A6 considerou a motivação para aprender as TD no sentido de ampliar o contato familiar e também a aprendizagem intergeracional como uma possibilidade de realização através de competências para a aprendizagem ao longo da vida.

Em vista disso, é possível atentar para a variabilidade de aspectos no que concerne a autoria digital no processo educacional de idosos. Dessa forma, destacam-se a vontade de aprender algo novo, a valorização e olhar atento aos temas de interesse dos idosos para criação dos conteúdos digitais e a necessidade de construir competências digitais.

\subsection{Oportunidades de pesquisas relacionadas à área de educação}

Em relação às oportunidades de pesquisas relacionadas à área da educação acerca da autoria ou competências digitais, verifica-se que $66,68 \%$ das pesquisas não informaram a respeito (A2; $A 4$; $A 5$; A6). Por outro lado, 33,33\% apontam a possibilidade de novas investigações sobre autoria digital de idosos por meio da construção de materiais digitais (A1; A3) e 16,67\% indicam cursos de inclusão digital (A1).

Nesse viés, A1 indicou duas oportunidades de pesquisa na área da educação, sendo a primeira, os cursos de inclusão digital destinados a este público, pois minimizam tanto a distância quanto a barreira tecnológica existente no âmbito intergeracionali. . A segunda enfatiza o desenvolvimento da autoria digital de idosos por meio da construção de materiais digitais. Nessa perspectiva, A3, apontam a necessidade de desenvolver atividades que estimulem a autoria digital e possibilitem a construção e reconstrução de significados em cursos de inclusão digital.

Por conseguinte, identificou-se que a maioria dos estudos não indicaram possibilidades de novos estudos no campo da educação. Entretanto, dos que apontaram, há uma predominância acerca de pesquisas de autoria digital de idosos com ênfase no processo de construção de materiais digitais. Por fim, um estudo indicou a necessidade de investigar os cursos de inclusão digital, visto que minimizam as barreiras intergeracionais. 


\subsection{Limites de pesquisas relacionadas à área de educação}

Em se tratando dos limites ou desafios relacionados à autoria digital ou competências na educação $33,33 \%$ não apontaram (A1; A3); $16,67 \%$ apontaram a escassez de bibliografia (A2); $16,67 \%$ indicaram a necessidade de desenvolver competências com vistas à inclusão digital e social (A4); $16,67 \%$ salientaram o desenvolvimento de conhecimentos e habilidades frente ao uso das TD (A5). Além disso, $16,67 \%$ a falta de equipamentos com acesso à Internet (A6) bem como falta locais públicos com livre acesso a internet (A6) e, por fim, um aspecto do envelhecimento a questão da memória (A6).

A principal limitação de pesquisa para A2 foi à escassez de bibliografias sobre o uso das tecnologias digitais de forma crítica, segura e consciente, tanto no trabalho como no lazer por parte do público sênior. Em A4 elencam como desafios a inclusão digital e social estarem atrelados a muitas áreas e competência a serem desenvolvidas. Nesse viés, sugere que "[...] cada cidadão deve focar-se nas utilizações e nos objetivos de acesso às tecnologias digitais/Internet e desenvolver esforços para adquirir as competências digitais de que mais necessita" (GIL, 2020, p. 158). Ademais, A5 elencam como limitação dos seniores a questão do conhecimento e como desafio a falta de habilidade em manusear tais tecnologias.

Quanto aos desafios A6 indicam a falta de equipamento informático e acesso à internet; a escassa oferta de locais públicos de acesso livre a computadores; custos elevados; pouca ou nenhuma experiência no uso das Tecnologias da Informação e Comunicação (TIC); falta de prática e algum esquecimento ou dificuldade em relembrar determinados procedimentos.

\subsection{Análise final dos artigos}

Em síntese, em relação às questões de pesquisa, observou-se que nenhum dos estudos selecionados apresentou a Autoria Digital como uma competência digital. Apenas em 16,67\% (A4) é feita uma breve relação entre o conceito de autoria com literacia. Além disso, em 83,35\% ( 1 ; $A 2 ; A 3 ; A 5 ; A 6)$ das pesquisas ou se falava em autoria ou em competência digital.

Na mineração textual, ao analisar todos os artigos, foi possível encontrar 86.874 termos e suas repetições. Dentre eles, as 25 palavras-chave, ou seja, aquelas com maior frequênciaxii. A Figura 2 apresenta a nuvem de palavras construída a partir desses termos esse resultado pode ser acessado em: https://voyant-tools.org/?corpus=d308af082afa09f544eca94e4fb239c9.

Figura 2: Nuvem de palavras-chave dos artigos aprovados.

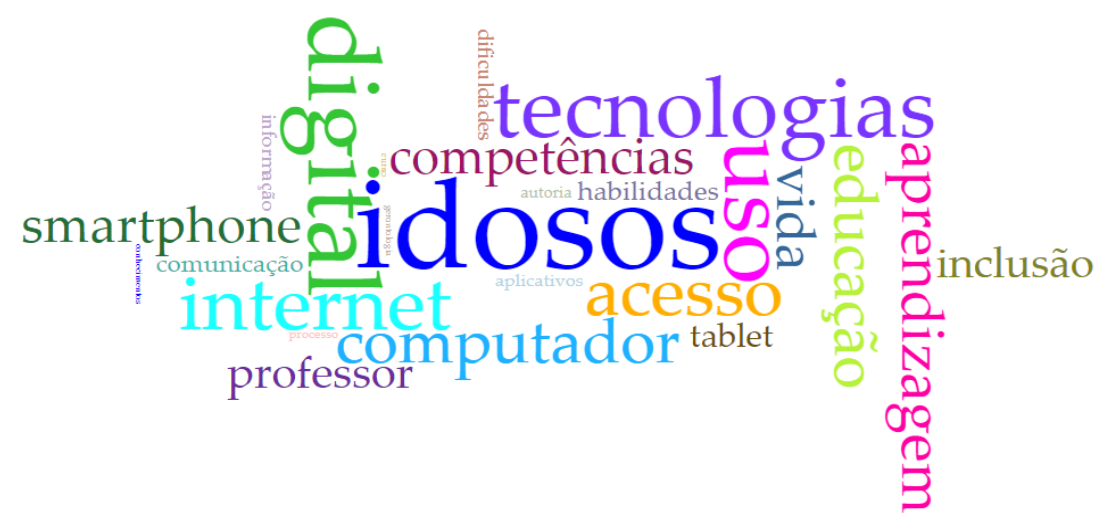

Fonte: as autoras (2021) 
A nuvem de palavras evidencia que nos estudos selecionados a inclusão digital de idosos surgem por meio de cursos educacionais que visam a aprendizagem das tecnologias digitais (smartphone, computador e tablet) como parte de um processo para a construção de competências digitais ou autoria. Em destaque há o papel do professor como um mediador que acompanha o estudante na construção do conhecimento e dá suporte em suas dificuldades. A visão de educação percebida nesse contexto é de que o docente ao ensinar não transfere conhecimento, mas, sobretudo "[...] cria as possibilidades para a sua produção ou a sua construção" (FREIRE, 2015, p. 47).

Paralelamente, foi gerada a ilustração de co-ocorrência das três palavras-chave principais ${ }^{\text {xiii: }}$ idosos, competências e autoria que podem ser visualizadas na Figura 3.

Figura 3: Ilustração de co-ocorrência das palavras-chave principais com ênfase nas suas cinco principais conexões.

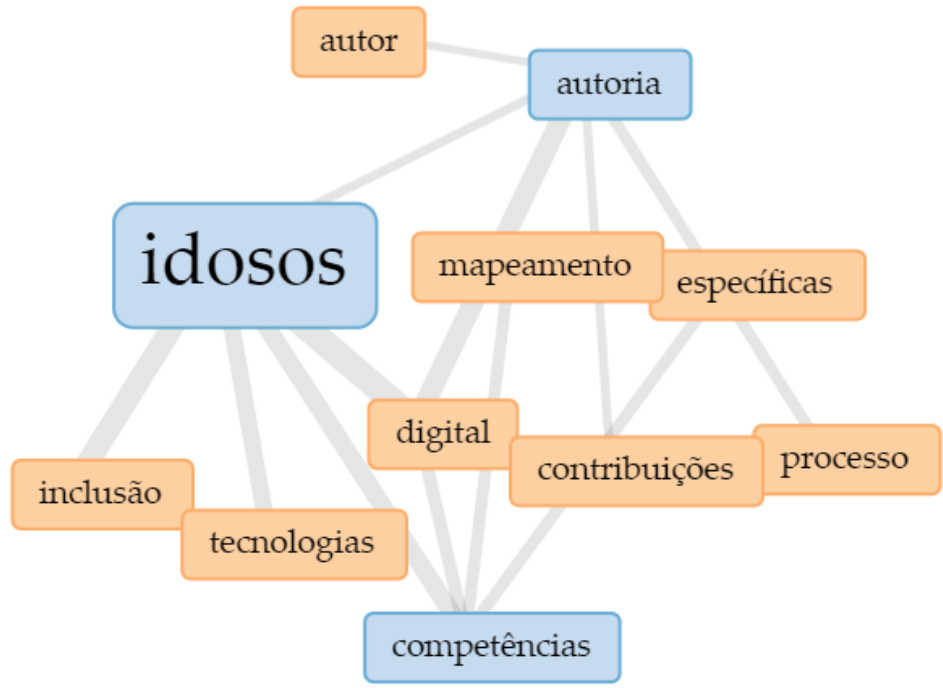

Fonte: as autoras (2021)

Observa-se que o termo autoria nos estudos selecionados não faz nenhuma relação direta com competências, mas estabelece conexão com idosos e com autor que nesse processo é digital. A palavra-chave competências está ligada diretamente aos seniores e ao contexto digital, evidenciando a necessidade de mapeamento para identificar as competências específicas. Assim, o vocábulo idoso liga-se à inclusão por intermédio das tecnologias digitais que se relacionam com competências e autoria.

A partir disso, foi possível perceber uma lacuna em relação à conexão de competências e autoria digital. Nesta pesquisa, compreende-se que a autoria digital é uma competência corroborando-se com as definições de André (2018) e (SLODKOWSKI, 2019). Assim, o processo mencionado pelos autores se refere à construção da competência autoria digital que ocorre em um âmbito educacional.

Logo, nesse contexto, Zabala e Arnau (2021) apontam que os alunos podem aplicar os conhecimentos em distintas situações quando a aprendizagem é significativa, ou seja, que se relaciona com suas vidas. Dessa forma, o interesse do público idoso em procurar cursos de inclusão digital para aprender acerca das tecnologias e criar materiais digitais estão crescendo (BARBOSA, 2021). Nesse viés Machado (2019) indica que as criações autorais pelos seniores podem contribuir na autovalorização e autoestima. 
Portanto, percebe-se que o conceito de autoria passou por transformações sócio-históricas-culturais nas quais adquiriu um novo papel associado à: expressão, reconhecimento, participação social e valorização. Nessa perspectiva, a educação busca acompanhar as inovações integrando as tecnologias digitais no processo de ensino e aprendizagem (BEHAR et al., 2019). Por conseguinte, a educação passou a incluir este conceito nas suas metodologias e práticas pedagógicas, pois por meio da autoria digital, seria possível propiciar ao idoso ser ator no processo de criação utilizando as tecnologias digitais. Por fim, na seção a seguir são apresentadas as considerações finais do estudo.

\section{CONSIDERAÇÕES FINAIS}

O aumento da expectativa de vida associado à ampliação do acesso às tecnologias digitais vem despertando o interesse de alguns idosos a respeito da criação de materiais digitais. Assim, no contexto educacional, os cursos de inclusão digital têm oportunizado espaços de construção da competência autoria digital. Nessa perspectiva, o presente estudo analisou a autoria e competências digitais de idosos no contexto da educação.

A partir dos resultados apresentados neste artigo, pode-se perceber uma lacuna em relação à conexão entre os conceitos de competências e autoria digital, pois em 83,35\% dos estudos os mesmos apareceram separados. Entretanto, nesta pesquisa, compreende-se que a autoria digital é uma competência. Ademais, constatou-se que em $100 \%$ dos estudos foi indicado que a inclusão digital de idosos surge através de cursos educacionais a fim de ensinar acerca das tecnologias digitais como parte de um processo para a construção de competências digitais.

Em relação aos limites desta investigação, ressalta-se que a partir dos dados analisados não foi possível identificar as motivações e principais interesses do público mais velho em produzir materiais digitais. Em vista disso, como trabalhos futuros observa-se a pertinência de mais investigações acerca da competência autoria digital na perspectiva da construção de materiais digitais por idosos bem como suas motivações. Além disso, destaca-se a relevância em identificar e analisar as normativas sobre direitos autorais nesse processo de criação.

Portanto, acredita-se que no âmbito educacional a construção desses materiais digitais autorais por idosos pode auxiliar tanto na compreensão do próprio processo de envelhecimento, quanto na aprendizagem ao longo da vida. Em vista disso, é necessário instigar a utilização das ferramentas de autoria em cursos de inclusão digital e, sobretudo, desenvolver estratégias que oportunizem a construção da competência digital de autoria por idosos.

\section{REFERÊNCIAS}

ANDRÉ, C. F. O pensamento computacional como estratégia de aprendizagem, autoria digital e construção da cidadania. Revista Digital de Tecnologias Cognitivas, n.18, p.94-109, 2018.

BEHAR, P. A. (org). Competências em educação a distância. Porto Alegre: Penso, 2013.

BEHAR, P. A (org). Recomendação Pedagógica em Educação a Distância. Porto Alegre: Penso, 2019.

BRANCO, Sérgio. Memória e esquecimento na internet. Porto Alegre: Arquipélago Editorial, 2017. 
CENTRO REGIONAL DE ESTUDOS PARA O DESENVOLVIMENTO DA SOCIEDADE DA INFORMAÇÃO (Cetic.br). Pesquisa sobre o uso das tecnologias de informação e comunicação nos domicílios brasileiros-TIC DOMICÍLIOS 2018. Disponível em: <https://data.cetic.br/cetic/explore?idPesquisa=TIC_DOM>. Acesso em: 16 jun. 2021.

CENTRO REGIONAL DE ESTUDOS PARA O DESENVOLVIMENTO DA SOCIEDADE DA INFORMAÇÃO (Cetic.br). TIC DOMICÍlIOS 2019 PRINCIPAIS RESULTADOS. Disponível em: <https://cetic.br/media/analises/tic_domicilios_2019_coletiva_imprensa.pdf>. Acesso em: 16 jun. 2021.

BARBOSA, M. 97\% dos idosos acessam a internet, aponta pesquisa da CNDL/SP. 2021. Disponível em:<https://cndl.org.br/varejosa/numero-de-idosos-que-acessam-a-internet-cresce-de68-para-97-aponta-pesquisa-cndl-spc-brasil/>. Acesso em: 17 jun. 2021.

NITAHARA, A. Ranking dos idosos. Mundo 2020. Proporção de idosos por países, Fundação Getúlio Vargas. Agência Brasil, 2020. Disponível em: < https://agenciabrasil.ebc.com.br/saude/noticia/2020-04/brasileiros-com-65-anos-ou-mais-sao-1053-da-populacao-diz-FGV >. Acesso em: 07 jun.2021.

FOUCAULT, Michel. O que é um autor? Lisboa: Passagens, 2009.

FREIRE, P. Pedagogia da autonomia. Saberes necessários à prática educativa. São Paulo: Editora Paz e Terra, 2015.

GIL, Henrique. Nativos digitais, migrantes digitais e adultos mais idosos: pontes para a infoinclusão. Revista Educação, Psicologia e Interfaces. v. 3 n. 2 . 2019. Disponível em:<https://educacaoepsicologia.emnuvens.com.br/edupsi/article/view/152>. Acesso em: 19 jan. 2021.

IBGE. Em 2019, expectativa de vida era de 76,6 anos. 2020 . Disponível em:<https://agenciadenoticias.ibge.gov.br/agencia-sala-de-imprensa/2013-agencia-denoticias/releases/29502-em-2019-expectativa-de-vida-era-de-76-6-anos>. Acesso em: 25 jun. 2021.

KITCHENHAM, B.; CHARTERS, S. Guidelines for performing systematic literature reviews in software engineering. In: Software Engineering Group, School of Computer Science and Mathematics, Keele University, p. 1-57, 2007.

LUCAS, M.; MOREIRA; A. DigComp - Quadro Europeu de Referência para a Competência Digital. Aveiro. Universidade de Aveiro - Laboratório de Conteúdos Digitais do CIDTFF, 2017.

MACHADO, L. R; BEHAR, P. A. Competências necessárias para os alunos idosos na educação a distância. In: BEHAR, P. A (Org.). Competências em Educação a Distância. 1ed. Porto Alegre: Penso, v. 1, p. 223-236, 2013.

MACHADO, L. R. Modelo de competências digitais para M-learning com foco nos idosos. Tese (Doutorado em Informática na Educação) - Universidade Federal do Rio Grande do Sul. Porto Alegre. 2019.

MACHADO, L. R; SONEGO, A. H; RIBEIRO, A. C. R; MENDES, J. S. S.; BEHAR, P. A. AUTORIA DIGITAL DE IDOSOS: A PRODUÇÃO DE INFOGRÁFICOS EM UM CURSO DE INCLUSÃO DIGITAL. Estud. interdiscipl. envelhec., Porto Alegre, v. 25, n. 1, p. 7-20, 2020. Disponível em: <https://seer.ufrgs.br/RevEnvelhecer/article/view/89047/58362>. Acesso em: 17 jun. 2021.

MACHADO, L. R.; GRANDE, T. P. F.; BEHAR, P. A.; LUNA, F, M, R. Mapeamento de competências 
digitais: a inclusão social dos idosos. ETD: Educação Temática Digital, v. 18, p. 903-921, 2016. Disponível em: <https://periodicos.sbu.unicamp.br/ojs/index.php/etd/article/view/8644207>. Acesso em: 20 jan. 2021.

MENEZES, M. E. L. Tecnologias e mídias digitais no processo educativo e a autoria de alunos: limites, contribuições e possibilidades. Dissertação (Mestrado em Educação) Faculdade de Educação, Pontifícia Universidade Católica de São Paulo. São Paulo. 2013.

PATRÍCIO, M. R. V; OSORIO, A. Literacia digital intergeracional: desafios e oportunidades para a educação ao longo da vida. EDUSER: revista de educação, v.9, n.1, 2017.

PATRÍCIO, M. R. V. Aprendizagem intergeracional com tecnologias de informação e comunicação. Tese (Doutorado em Ciências da Educação) - Instituto de Educação, Universidade do Minho. Portugal. 2014.

PERRENOUD, P. Dez Novas Competências para Ensinar. Porto Alegre: Artmed Editora, 1999.

PERRENOUD, P. Desenvolver competências ou ensinar saberes? A escola que prepara para a vida. Porto Alegre: Penso, 2013.

SILVA, K. K; BEHAR, P. A. Competências digitais na educação: uma discussão acerca do conceito. Educação em revista. Belo Horizonte. v. 35. 2019.

SLODKOWSKI, B. K. Competências digitais: um olhar sobre a construção de materiais digitais por idosos. (Monografia)- Faculdade de Educação, Universidade Federal do Rio Grande do Sul. Porto Alegre. 2019. Disponível em: <https://lume.ufrgs.br/handle/10183/199170>. Acesso em: 17 jun. 2021.

SLODKOWSKI, B. K; MACHADO, L. R; MENDES, J. S. S; BEHAR, P. A. Autoria digital de cybersêniors: um estudo de caso sobre a construção de vídeos. Informática Na Educação: teoria e prática, Porto Alegre, v. 22, n. 3, p.12-25, set./dez. 2019.

TEIXEIRA, M. S.; ANDRADE, E. R. O SUJEITO NAS REDES SOCIAIS: UMA ANÁLISE DISCURSIVA DA AUTORIA. Macabéa - Revista Eletrônica do Netlli. v. 9, n.1, p. 497-518, out/dez. 2020.

ZABALA, A; ARNAU, L. Métodos para ensinar competências. Porto Alegre: Penso, 2020.

Submissão: 01/07/2021

Aceito: 10/07/2021

\footnotetext{
'Emoji: para o dicionário de significados on-line (https://www.significados.com.br/emoji/), um emoji é um pictograma, isto é, uma imagem que transmitem a ideia de uma palavra ou frase completa. De acordo com Paiva (2016), esses pictogramas surgiram no mundo digital, são chamados de emojis, e são populares, sobretudo, em redes sociais e em comunicações de troca de mensagens instantâneas.

ii Disponível em: <https://dl.acm.org/>. Acesso em: 05 nov. 2020.

iii Disponível em: <https://www.sciencedirect.com/>. Acesso em: 05 nov. 2020.

iv Disponível em: <https://scielo.org/>. Acesso em: 05 nov. 2020.

v Disponível em: <https://scholar.google.com.br/?hl=pt>. Acesso em: 05 nov. 2020.

vi Disponível em: < https://www.scopus.com/>. Acesso em: 05 nov. 2020.
} 
vii Disponível em: <https://seer.ufrgs.br/RevEnvelhecer/search>. Acesso em: 05 nov. 2020.

viii Disponível em: <https://sabi.ufrgs.br/>. Acesso em: 05 nov. 2020.

ix Disponível em: <https://www.fc.unesp.br/\#!/ciedu>. Acesso em: 05 nov. 2020.

× Disponível em: <https://periodicos.ufmg.br/index.php/edrevista/index>. Acesso em: 05 nov. 2020.

xi De acordo com o dicionário Larousse o termo intergeracional está relacionado com o que se estabelece/realiza entre duas ou mais gerações. Disponível em: <https://www.dicio.com.br/intergeracional/>. Acesso em: 07 dez. 2020. Desse modo, no contexto educacional, Patrício (2014) salienta que um modo de ocorrer à aprendizagem intergeracional é unindo jovens e idosos em torno de um diálogo sobre tecnologias.

xii As 25 palavras-chaves com suas respectivas frequências, são: idosos $(n=478)$, digital $(n=375)$, uso $(n=284)$, tecnologias $(n=280)$, internet $(n=252)$, acesso $(n=194)$, computador $(n=176)$, educação $(n=167)$, aprendizagem $(n=167)$, vida $(n=159)$, smartphone $(n=148)$, competências $(n=143)$, professor $(n=135)$, inclusão $(n=128)$, tablet $(n=113)$, habilidades $(n=98)$, comunicação $(n=92)$, dificuldades $(n=88)$, informação $(n=85)$, aplicativos $(n=84)$, autoria $(n=81)$, gerontologia $(n=65)$, conhecimentos $(n=62)$, processo $(n=75)$, curso $(n=72)$.

xiii Os resultados do gráfico das três palavras-chaves principais podem ser vistos de modo interativo neste link: <https://voyant-tools.org/?corpus=d308af082afa09f544eca94e4fb239c9\&stopList=keywords-

25d598ddd640d315fb46c789a420a8c1\&query=compet\%C3\%AAncias\&query=compet\%C3\%AAncia\&query= idosos\&query=autoria\&mode=corpus\&view=CollocatesGraph>. Acesso em: 25 nov. 2020. 